\title{
Colour Evaluation of Pinot Noir and Merlot Wines after Malolactic Fermentation Carried out by Oenococcus oeni and Lactobacillus plantarum Patagonian Native Strains
}

\author{
N. T. Olguin ${ }^{1,2^{*}}$, L. Delfederico ${ }^{1}$, L. Semorile ${ }^{1,3}$
}

(1) Laboratorio de Microbiología Molecular, Instituto de Microbiología Básica y Aplicada (IMBA), Departamento de Ciencia y Tecnología, Universidad Nacional de Quilmes, Roque Sáenz Peña № 352, (B1876BXD) Bernal, Buenos Aires, Argentina

(2) Consejo Nacional de Investigaciones Científicas y Técnicas (CONICET), Godoy Cruz 2290 (C1425FQB) CABA, Argentina

(3) Comisión de Investigaciones Científicas de la Provincia de Buenos Aires (CIC-BA), Argentina

Submitted for publication: May 2020

Accepted for publication: October 2020

Keywords: Oenococcus oeni, Lactobacillus plantarum, lactic acid bacteria, malolactic fermentation, wine colour, tannins, polyphenols

\begin{abstract}
Malolactic fermentation is a complex process that involves many reactions aside from the decarboxylation of L-malic acid. But we still have only glimpses of that complexity. It is not clear if the phenolic composition and colour are affected by malolactic fermentation and, if so, to what extent. So, the aims of this study were: 1) to evaluate the behaviour of native Patagonian strains of Oenococcus oeni and Lactobacillus plantarum in two wine varieties, and 2) to analyse the effect of malolactic fermentation on the colour of these wines. Our results show that the survival of bacteria and L-malic acid decarboxylation is different depending on the lactic acid bacteria strain employed and the wine variety. In addition, we found that $O$. oeni can survive in wine even when L-malic acid is not being consumed. We found some correlations between MLF and colour-related parameters in Pinot noir but not for Merlot. In fact, some of the colour-related parameters measured in Merlot (total polyphenolic index, colour intensity, hue, as well as the CIELAB parameters) were affected even when L-malic acid was not being consumed.
\end{abstract}

\section{INTRODUCTION}

Malolactic fermentation (MLF), which is carried out by lactic acid bacteria (LAB), is desired in most red and some white and sparkling base wines (Bartowsky, 2017). The first three advantages given by this process are widely known: i) it deacidifies wine due to the decarboxylation of L-malic acid into the softer L-lactic acid; ii) it improves wine aroma by the production of secondary metabolites; and iii) it improves microbiological stability due to the consumption of the remaining carbon and energy sources.

During the last few decades, MLF has been proven to be a much more complex process due to the complexity and variability of LAB metabolism (Vivas et al., 1994; Bartowsky, 2017). MLF modifies organoleptic parameters and affects the aroma profile (Brizuela et al., 2017, 2018) and colour parameters (Hernández et al., 2007; Massera et al., 2009; Abrahamse \& Bartowsky, 2012; Burns \& Osborne, 2013; Izquierdo-Cañas et al., 2016). Besides colour parameters, we need to consider the astringency and bitterness, as all these wine attributes are related to the grape phenolic composition. While colour is conferred by molecules called anthocyanins, astringency and bitterness are related to polyphenolic compounds known in general as tannins and, more specifically, condensed tannins or proanthocyanidins (Cheynier et al., 2006; Garrido \& Borges, 2013; Nel, 2018). Information about MLF affecting wine phenolic composition and colour is still scarce. In Argentina, there is only one study confirming this relationship using wines from the Malbec grape variety (Paladino et al., 2001). The change in colour parameters is complex and depends on grape variety, terroir, viticulture and oenological practices (including the alcoholic fermentation and yeast strain), as well as LAB species and strain (Versari et al., 2008; Dobrei et al., 2010; Mangani et al., 2011). Oenococcus oeni is the first species to be recognised as responsible for MLF, since it is the best adapted to the wine conditions and the main bacterium responsible for MLF in many countries and wineries (Lonvaud-Funel, 2015; Lorentzen \& Lucas, 2019; Sumby et al., 2019). Lactobacillus plantarum is starting to

\footnotetext{
*Corresponding author: E-mail address: ntolguin@gmail.com

Acknowledgements: This work was funded by grants from Universidad Nacional de Quilmes (Programa I+D UNQ Microbiología Básica y Aplicada a Agronomía, Alimentos y Salud 2019-2023 - Resolución (R) No 1255/19); and the Agencia Nacional de Promoción Cientifica y Tecnológica (ANPCyT, PICT $2017 N^{\circ}$ 1156). LS is member of the Research Career of CIC-BA; NTO is member of the Research Career of CONICET. LD is a research member of UNQ. NTO would also like to thank Dr Nikolaos Kontoudakis (Agricultural University of Athens, Athens, Greece) for his support and collaboration in the analysis of the results
} 
be used as a starter culture, since it has been proven to be able to carry out MLF as well as O. oeni (Du Toit et al., 2011; Berbegal et al., 2016; Brizuela et al., 2019; KriegerWeber et al., 2020). For instance, Lb. plantarum is available commercially, as well as in the co-inoculant bacterial starter with both the $O$. oeni and Lb. plantarum strains.

As more information is obtained thanks to wine research and new techniques are being applied in this field, more questions arise. There is still little or no information about $O$. oeni and Lb. plantarum modifying wine colour and astringency sensations. And even when most winemakers recognise the importance of carrying out MLF, they are still reluctant to perform a deep analysis of their wines in relation to this subject. Due to the need to know more about the interaction of LAB, MLF, grape variety, wine colour and astringency, we decided to contribute to this paradigm. The aim of this research was to evaluate the MLF performance of two Patagonian native strains, one of $O$. oeni and one of Lb. plantarum, plus two additional strains (O. oeni ATCC 27310 and $\mathrm{Lb}$. plantarum ATCC 14917), and to relate their performance to the colour of the wine and the phenolic content using the Pinot noir and Merlot grape varieties.

\section{MATERIALS AND METHODS}

\section{Microvinifications and experimental design}

Microvinifications were carried out on a laboratory scale using $2 \mathrm{~kg}$ of must from two grape varieties, Pinot noir and Merlot, harvested from vineyards located in General Roca, North Patagonia, Argentina in 2018. The must was fermented in one container for each variety by inoculation with the commercial yeast strain, Saccharomyces cerevisiae bayanus, Lalvin QA23 (Lallemand BIO S.L.), according to the manufacturer's instructions. The alcoholic fermentation (AF) was monitored every two days by measuring the temperature and density of the must, and a pigeage was performed each time to favour phenolic compounds dissolution. The temperature of the fermenting must was stable, at around $21^{\circ} \mathrm{C}$, and the process took 14 days for Pinot noir and 21 days for Merlot. At the end of AF, the ethanol concentration was $13 \%(\mathrm{v} / \mathrm{v})$ in the Pinot noir and $14.5 \%(\mathrm{v} / \mathrm{v})$ in the Merlot. At this point, both wines contained approximately $13 \mathrm{mg} / \mathrm{L}$ free sulphur dioxide. After AF, the wines were separated from the skins and then sterilised by filtration through a $0.2 \mu \mathrm{m}$ pore size filter (Sartorius Stedim Biotech Gmbh, Göttingen, Germany). Then, $50 \mathrm{~mL}$ of each wine was poured into each of ten sterile glass flasks before inoculation with lactic acid bacteria.

\section{Growth conditions and MLF}

The two O. oeni strains (ATCC 27310 (OeATCC 27310) and UNQOe19 (KY561603, CP027431)) and the two Lb. plantarum strains (ATCC 14917 (LpATCC 14917) and UNQLp11 (CP031140)) were cultured at $28^{\circ} \mathrm{C}$ in tubes containing MRS broth medium supplemented with L-malic acid $(4 \mathrm{~g} / \mathrm{L})$ and fructose $(5 \mathrm{~g} / \mathrm{L})$ at $\mathrm{pH} 5.0$. After $48 \mathrm{~h}$, cells were harvested by centrifugation and resuspended in the acclimation medium $(50 \mathrm{~g} / \mathrm{L}$ MRS, $40 \mathrm{~g} / \mathrm{L}$ fructose, $20 \mathrm{~g} / \mathrm{L}$ glucose, $4.5 \mathrm{~g} / \mathrm{L}$ L-malate, $1 \mathrm{~g} / \mathrm{L}$ Tween $80,0.1 \mathrm{mg} / \mathrm{L}$ pyridoxine, $\mathrm{pH} 4.6)$ containing $6 \%(\mathrm{v} / \mathrm{v})$ ethanol (BravoFerrada et al., 2014). The acclimation tubes were cultured at $21^{\circ} \mathrm{C}$ for $48 \mathrm{~h}$, after which cells (approximately $10^{8} \mathrm{CFU} / \mathrm{mL}$ ) were harvested by centrifugation and inoculated into the sterile wines (prepared as described above). From these 10 flasks, two were left without inoculation, as they were the control condition. The other eight flasks were inoculated with each of the four strains by duplicate and then kept at an incubation temperature of $21^{\circ} \mathrm{C}$. Cell survival was analysed every two days at the beginning of MLF, and then every five days until approximately the 35 th day, by counting colonies on plates of MRS medium supplemented as described above. L-malic acid consumption was measured using the L-malic Acid Enology Enzymatic kit (BioSystems SA, Barcelona, Spain) according to the manufacturer's instructions.

\section{Wine chemical analysis}

Both wines were analysed for $\mathrm{pH}$, ethanol and free sulphur dioxide concentrations according to the methods recommended by the OIV (2009). The total polyphenol index (TPI) was determined following the method described by Ribéreau-Gayon et al. (2006). Briefly, wines samples were diluted to 1:100 and then absorbance was measured at $280 \mathrm{~nm}$ in a cuvette of $1 \mathrm{~cm}$ optical path. The results were multiplied by the dilution factor. Total tannins were determined by absorbance measurement at $550 \mathrm{~nm}$, after acid hydrolysis of the samples as described by Elorduy Vidal (2014). Colour intensity (IC) was estimated by summing the absorbance values at 420, 520 and $620 \mathrm{~nm}$ (Glories, 1984), and the hue was determined as the ratio between the values obtained at 420 and $520 \mathrm{~nm}(\mathrm{~A} 420 / 520)$. The CIELAB parameters, lightness $\left(L^{*}\right)$, chroma $\left(C^{*}\right)$, hue $\left(H^{*}\right)$, redness $\left(a^{*}\right)$ and yellowness $\left(b^{*}\right)$, were determined according to Ayala et al. (1997). The total anthocyanin (TA) content was determined as described by Durán and Trujillo (2008), using a sulphur dioxide bleaching protocol with some modifications according to Pandeya et al. (2018). Two tubes were used for each wine sample, both containing $100 \mu \mathrm{L}$ of wine, $100 \mu \mathrm{L}$ of $\mathrm{HCl}$ in ethanol $(0.1 \%)$, and $200 \mu \mathrm{L}$ aqueous $\mathrm{HCl}(20 \%)$. A total of $440 \mu \mathrm{L}$ of water was then added to tube A and $440 \mu \mathrm{L}$ of potassium bisulphite $(26 \%)$ solution was added to tube B. Both mixtures were diluted 1:1 and absorbance was measured at $520 \mathrm{~nm}$ after $20 \mathrm{~min}$, against a blank $(500 \mu \mathrm{L}$ $\mathrm{HCl}$ in ethanol $(0.1 \%)$, and $1 \mathrm{~mL}$ aqueous $\mathrm{HCl}(20 \%)$ and $2.7 \mathrm{~mL}$ water). The TA content was then quantified using the formula TA $(\mathrm{mg} / \mathrm{L})=875\left(\Delta \mathrm{A}_{520}\right)$.

\section{RESULTS}

\section{Cell survival and MLF performance in wine}

The four LAB strains behaved differently depending on the wine (Fig. 1). O. oeni survived and maintained its viability in Pinot noir wine (Fig. 1a). A difference in the rate at which L-malic acid was converted by $O$. oeni ATCC 27310 (OeATCC 27310) and UNQOe19 was evident, with the former being more active (Fig. 1c). Both Lb. plantarum strains, ATCC 14917 (LpATCC 14917) and UNQLp11, presented similar behaviour in terms of population survival and L-malic acid consumption (Fig. 1a and 1c).

In Merlot wine, both $O$. oeni strains slowly decreased their viability (Fig. 1b), with OeATCC 27310 being the one that was able to keep its viability stable at $1 \times 10^{4}$ $\mathrm{CFU} / \mathrm{mL}$ until the end of analysis, despite no L-malic acid 
consumption being detected by either $O$. oeni strain (Fig. 1d). Lb. plantarum UNQLp11 maintained its viability for at least ten days (Fig. 1b) and then decreased abruptly, but it was the only strain able to consume almost all L-malic acid (Fig. 1d). LpATCC 14917 decreased its population as soon as it was inoculated into wine and, accordingly, no L-malic acid consumption was registered.

\section{Colour parameters in Pinot noir wine with and without MLF}

Table 1 shows the different parameters that were measured in the Pinot noir wine with and without MLF, inoculated, or not inoculated (no-MLF). The no-MLF condition (control) corresponds to the wine sample filtrated after alcoholic fermentation but not inoculated. The $\mathrm{pH}$ was higher only in the wine samples in which MLF fermentation was successful, i.e. samples inoculated with $O$. oeni strains. Tannins (TAN) were significantly reduced in the wine inoculated with LpATCC 14917, whereas colour intensity (CI) was significantly increased in the wine inoculated with strain UNQOe19 compared to all other conditions. The hue values, calculated as the ratio of the absorbances obtained at 420 and $520 \mathrm{~nm}(\mathrm{~A} 420 / 520)$, were significantly higher in wines inoculated with the Oenococcus strains and with the LpATCC 14917 strain. Also, the values of redness (a*) were significantly lower than in the control condition, and in the conditions where MLF was not successful (wines inoculated with Lactobacillus strains). Although not statistically significant, our results show a decrease in chroma $\left(C^{*}\right)$ and an increase in hue $\left(H^{*}\right)$ in the samples in which MLF was successful (samples inoculated with Oenococcus) in comparison with all other conditions. Finally, we found that colorimetric differences $\left(\Delta E^{*}\right)$ between the inoculated samples and the control condition (no-MLF) were higher than 2.7 CIELAB units and that these differences were higher in wines in which MLF was successful.

Colour parameters in Merlot wine with and without MLF Table 2 shows the different parameters that were measured in Merlot wine with and without MLF, inoculated or not inoculated (no-MLF). The no-MLF condition (control) corresponds to the wine sample filtrated after alcoholic fermentation but not inoculated. In this grape variety, only UNQLp11 was able to complete MLF, which is reflected in the higher modification in $\mathrm{pH}$ even when there is also a significant difference in the $\mathrm{pH}$ value for samples in which MLF was unsuccessful (UNQOe19 and LpATCC 14917). A significant increase in the total phenolic index (TPI) was observed in the wine inoculated with strain LpATCC 14917, whereas a slight though not statistically significant increase was detected in wines inoculated with Oenococcus strains. Only the wine sample with a successful MLF (wine inoculated with UNQLp11) maintained a similar TPI value to the control condition (no-MLF). The colour intensity (CI) was significantly increased in samples inoculated with Lactobacillus strains and with OeATCC 27310. The hue values, calculated as the ratio of the absorbances obtained at 420 and $520 \mathrm{~nm}$ (A420/520), were significantly higher in wines inoculated with Lactobacillus, although a slight increase was also found in wines inoculated with Oenococcus, in comparison with the control condition.

Almost all CIELAB parameters presented a significantly different value to that of the control condition (no-MLF). The lightness $\left(L^{*}\right)$ was reduced in all the inoculated wines, but
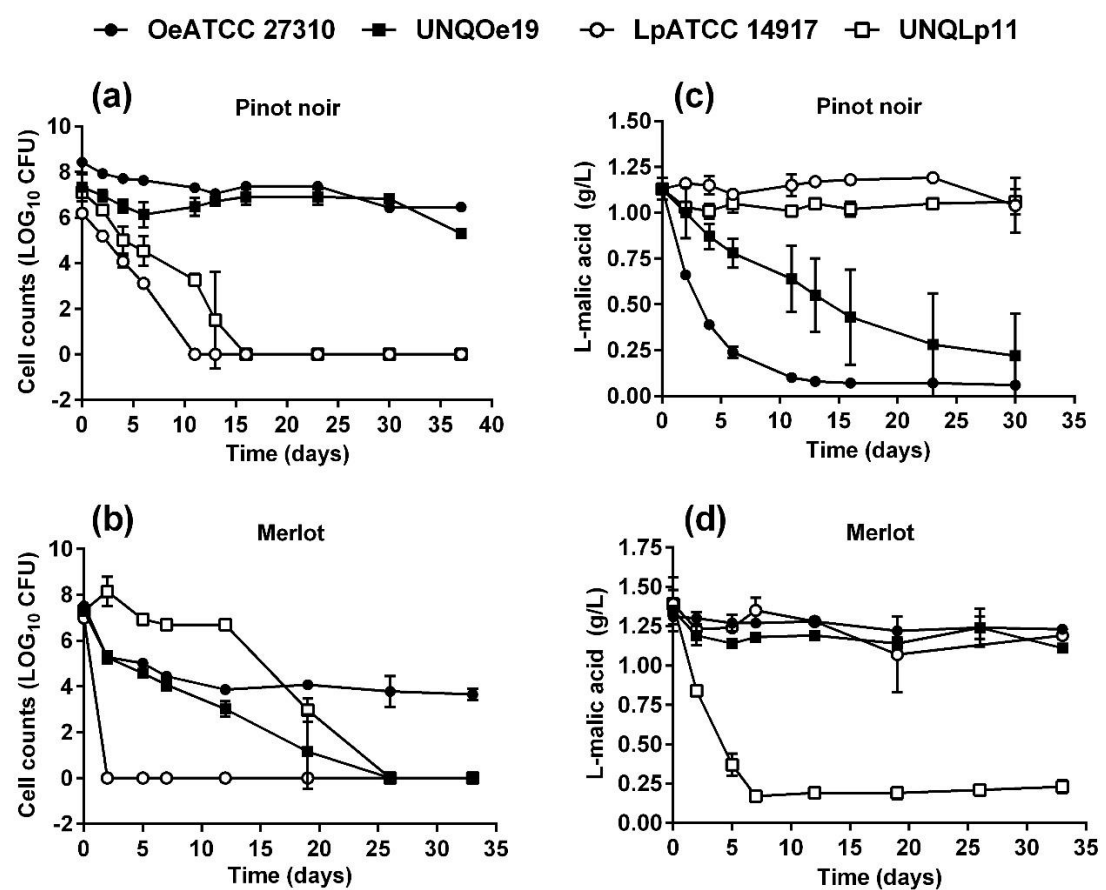

FIGURE 1

Survival and MLF performance of $O$. oeni and Lb. plantarum strains in Pinot noir and Merlot wines. 
TABLE 1

Colour parameters of Pinot noir wine samples inoculated with different LAB strains.

\begin{tabular}{|c|c|c|c|c|c|}
\hline & \multicolumn{5}{|c|}{ Pinot noir } \\
\hline & no-MLF & ОеАТСС 27310 & UNQOe19 & LpATCC 14917 & UNQLp11 \\
\hline pH & $3.61 \pm 0.01$ & $3.82 \pm 0.01^{*}$ & $3.79 \pm 0.05^{*}$ & $3.59 \pm 0.04$ & $3.62 \pm 0.01$ \\
\hline${ }^{1} \mathrm{TPI}$ & $32.1 \pm 0.55$ & $33.97 \pm 0.02$ & $33.06 \pm 0.28$ & $32.79 \pm 0.1$ & $33.62 \pm 1.46$ \\
\hline${ }^{2} \mathbf{T A N}$ & $0.841 \pm 0.05$ & $0.812 \pm 0.02$ & $0,791 \pm 0.01$ & $0.756 * \pm 0.01$ & $0.798 \pm 0.01$ \\
\hline${ }^{3} \mathbf{T A}$ & $67.3 \pm 7.67$ & $79.3 \pm 3.71$ & $74.9 \pm 4.46$ & $61.6 \pm 6.69$ & $68.5 \pm 3.83$ \\
\hline${ }^{4} \mathrm{CI}$ & $5.06 \pm 0.35$ & $5.41 \pm 0.17$ & $5.86 \pm 0.52 *$ & $4.83 \pm 0.04$ & $5.04 \pm 0.04$ \\
\hline${ }^{5} \mathrm{~A} 420 / 520$ & $1.023 \pm 0.07$ & $1.184 \pm 0.04 * *$ & $1.147 \pm 0.04 * *$ & $0.944 \pm 0.01^{*}$ & $0.97 \pm 0.01$ \\
\hline $\mathbf{L}^{*}$ & $65.5 \pm 0.99$ & $61.65 \pm 5.3$ & $63.25 \pm 1.91$ & $68.15 \pm 1.34$ & $64.75 \pm 0.64$ \\
\hline$C^{*}$ & $114.25 \pm 2.47$ & $107.9 \pm 4.81$ & $108.6 \pm 1.13$ & $117.55 \pm 0.21$ & $115.2 \pm 0.14$ \\
\hline $\mathbf{H}^{*}$ & $42.6 \pm 0.54$ & $47.17 \pm 0.17$ & $45.7 \pm 0.98$ & $42.05 \pm 0.81$ & $42.92 \pm 0.12$ \\
\hline$a^{*}$ & $84.11 \pm 2.52$ & $73.36 \pm 3.48^{*}$ & $75.85 \pm 0.54^{*}$ & $87.29 \pm 1.24$ & $84.37 \pm 0.25$ \\
\hline$b^{*}$ & $77.31 \pm 0.85$ & $79.13 \pm 3.29$ & $77.73 \pm 2.1$ & $78.71 \pm 1.12$ & $78.45 \pm 0.11$ \\
\hline$\Delta \mathrm{E}^{*}$ & & $12.03 \pm 1.87$ & $8.70 \pm 2.73$ & $4.65 \pm 3.82$ & $2.71 \pm 0.13$ \\
\hline
\end{tabular}

${ }^{1} \mathrm{TPI}$, total polyphenolic index; ${ }^{2} \mathrm{TAN}$, tannins are expressed in $\mathrm{g} / \mathrm{L} ;{ }^{3} \mathrm{TA}$, total anthocyanins are expressed in $\mathrm{mg} / \mathrm{L} ;{ }^{4} \mathrm{CI}$, colour intensity; ${ }^{5} \mathrm{~A} 420 / 520$, hue calculated as the ratio of the absorbances obtained at 420 and $520 \mathrm{~nm}$. The statistical analysis was performed against the control (no-MLF) condition. Asterisks indicate that means differed significantly at $* p<0.05, * * 0.01$ (or less) from the control condition.

it was lower in wines inoculated with Lactobacillus strains, and even lower in the one inoculated with UNQLp11. No change was observed in the chroma $\left(C^{*}\right)$, hue $\left(H^{*}\right)$, redness $\left(a^{*}\right)$ and yellow-blue component $\left(b^{*}\right)$ presented the lower values. The only CIELAB parameter that showed a different trend was the colorimetric difference $\left(\Delta E^{*}\right)$. All samples presented higher values than 2.7 CIELAB units, but there were significant differences among them. The $\Delta E^{*}$ values in wines inoculated with OeATCC 27310 and UNQOe19 were statistically equal, whereas the $\Delta E^{*}$ value in the wine inoculated with UNQLp11 was statistically different and higher.

\section{Comparison of changes in colour parameters between wine varieties}

Table 3 shows the general increase or decrease in the different colour parameters in wines that were inoculated with the different LAB strains and in which consumption of L-malic acid occurred (MLF+), or where no L-malic acid was consumed (MLF-), based on the results from Table 1 and Table 2. The increase or diminution of values is indicated by arrows (double arrows when values are statistically different) with reference to the control condition (no-MLF), not included in this table. It is difficult to generalise, but it seems that the occurrence of MLF has different effects on some of the colour parameters, depending on the wine variety. For instance, the total anthocyanin (TA) content increased when MLF was successful, but only in Merlot, as it was not clear in Pinot noir. On the other hand, the hue (A420/520) increased with successful MLF in Pinot noir, but not in Merlot. The chroma $\left(C^{*}\right)$ diminished after MLF, whereas it increased when MLF was not successful in Pinot noir. In Merlot, the chroma $\left(C^{*}\right)$ diminished in all samples, as also did lightness $\left(L^{*}\right)$, hue $\left(H^{*}\right)$, redness $\left(a^{*}\right)$ and yellowness $\left(b^{*}\right)$.

\section{DISCUSSION}

We evaluated the MLF performance of four strains, two of $O$. oeni and two of Lb. plantarum, and found out that they behave differently depending on the wine variety, and thus the wine chemistry. O. oeni consumed L-malic acid in Pinot noir but not in Merlot, and one strain of $L b$. plantarum consumed L-malic acid in Merlot but not in Pinot noir. We also found that $O$. oeni can survive in wine even when L-malic acid is not being consumed.

Our second goal was to find out if there was a relationship between the MLF conducted by each strain and the wine colour, but we were unable to do so due to the uneven results in viability and L-malic acid consumption. However, our results show that some colour parameters can change even when MLF is not successful.

The strains used in this work were selected according to previous studies (Brizuela et al., 2017; Olguin et al., 2019), except for LpATCC 14917. The latter strain was selected for comparison purposes and it was the first time it was used in our studies, so its performance was new to us. It was surprising to discover that OeATCC 27310 was able to maintain a higher viability than the selected native UNQOe19 strain in Merlot wine, even when none of the employed $O$. oeni strains consumed L-malic acid in this wine variety. Renouf et al. (2007) found viable LAB -most of them $O$. oeni - in aged Bordeaux wines. These results again highlight the ability of $O$. oeni to survive under stressful conditions (Lonvaud-Funel, 2015; Sumby et al., 2019). It might be useful to search for additional acclimation 
TABLE 2

Colour parameters of Merlot wine samples inoculated with different LAB strains.

\begin{tabular}{|c|c|c|c|c|c|}
\hline & \multicolumn{5}{|c|}{ Merlot } \\
\hline & no-MLF & ОеАТСС 27310 & UNQOe19 & LpATCC 14917 & UNQLp11 \\
\hline pH & $3.53 \pm 0.01$ & $3.55 \pm 0.0$ & $3.6 \pm 0.01 * *$ & $3.58 \pm 0.01 *$ & $3.67 \pm 0.0 * *$ \\
\hline${ }^{1} \mathrm{TPI}$ & $46.32 \pm 0.18$ & $47.34 \pm 0.01$ & $47.56 \pm 0.47$ & $48.74 \pm 0.7 *$ & $46.72 \pm 0.42$ \\
\hline${ }^{2} \mathbf{T A N}$ & $1140 \pm 0.02$ & $1161 \pm 0.04$ & $1192 \pm 0.04$ & $1110 \pm 0.09$ & $1086 \pm 0.02$ \\
\hline${ }^{3} \mathbf{T A}$ & $108.8 \pm 13.8$ & $98.3 \pm 16.58$ & $123.7 \pm 10.95$ & $103.5 \pm 12.37$ & $131.6 \pm 1.05$ \\
\hline${ }^{4} \mathbf{C I}$ & $8.29 \pm 0.04$ & $9.04 \pm 0.53 *$ & $8.82 \pm 0.17$ & $9.29 \pm 0.33 * *$ & $9.54 \pm 0.09 * *$ \\
\hline${ }^{5} \mathrm{~A} 420 / 520$ & $0.772 \pm 0.0$ & $0.830 \pm 0.0$ & $0.834 \pm 0.0$ & $0.857 \pm 0.1 *$ & $0.857 \pm 0.0^{*}$ \\
\hline $\mathbf{L}^{*}$ & $50.55 \pm 1.91$ & $37.85 \pm 0.35^{* *}$ & $37.4 \pm 0.14 * *$ & $34.2 \pm 0.14 * *$ & $32.35 \pm 0.07 * *$ \\
\hline$C^{*}$ & $120.9 \pm 4.38$ & $97.53 \pm 0.7 * *$ & $96.02 \pm 0.08 * *$ & $90.09 \pm 0.33 * *$ & $85.88 \pm 0.04^{* *}$ \\
\hline $\mathbf{H}^{*}$ & $43.34 \pm 0.25$ & $41.14 \pm 0.08 * *$ & $41.17 \pm 0.08^{* *}$ & $40.09 \pm 0.07 * *$ & $39.69 \pm 0.1 * *$ \\
\hline$a^{*}$ & $87.94 \pm 2.86$ & $73.45 \pm 0.43^{*}$ & $72.28 \pm 0.03 *$ & $68.92 \pm 0.17 *$ & $66.09 \pm 0.13^{* *}$ \\
\hline $\mathbf{b}^{*}$ & $83 \pm 3.4$ & $64.16 \pm 0.57 *$ & $63.2 \pm 0.15^{*}$ & $58.02 \pm 0.3^{* *}$ & $54.85 \pm 0.09 * *$ \\
\hline$\Delta \mathrm{E}^{*}$ & & $28.74 \pm 3.08^{\mathrm{a}}$ & $30.24 \pm 2.47^{\mathrm{a}}$ & $37.18 \pm 1.93$ & $41.78 \pm 2.36^{b}$ \\
\hline
\end{tabular}

${ }^{1} \mathrm{TPI}$, total polyphenolic index; ${ }^{2} \mathrm{TAN}$, tannins are expressed in $\mathrm{g} / \mathrm{L} ;{ }^{3} \mathrm{TA}$, total anthocyanins are expressed in $\mathrm{mg} / \mathrm{L} ;{ }^{4} \mathrm{CI}$, colour intensity; ${ }^{5} \mathrm{~A} 420 / 520$, hue calculated as the ratio of the absorbances obtained at 420 and $520 \mathrm{~nm}$. The statistical analysis was performed against the control condition. Asterisks indicate that means differ significantly at $* p<0.05, * * 0.01$ (or less) from the control (no-MLF) condition. Letters denote significant difference between Oenococcus and Lactobacillus

conditions, as different strains may not respond and become activated in the same way.

When analysing the colour parameters, we found that some of them changed significantly in comparison to the control condition (no-MLF), even when no L-malic acid was consumed (MLF-) and particularly in the Merlot wine. But when consumption of L-malic acid occurred (MLF+), the changes in those colour parameters were even higher (UNQLp11). We also observed that some of the CIELAB parameters changed in the samples in which no L-malic acid was consumed (MLF-) in both wines. Some authors suggest that the variation, especially the decrease in wine colour, could be attributed to the absorption of polyphenols by LAB cell walls (Costantini et al., 2009; Burns \& Osborne, 2013), the increase in $\mathrm{pH}$ or the LAB strain involved, which is an ongoing discussion (Costello et al., 2012; Burns \& Osborne, 2013). In the case of $\mathrm{pH}$ variation, we could not explain why there was a significant increase in samples in which L-malic acid was not consumed. As $\mathrm{pH}$ and acidity are not only related to MLF (Comuzzo \& Battistutta, 2019), we will consider additional analyses in the future.

We agree that the different parameters that determine wine colour, astringency and bitterness may be modified according to LAB species or even strains carrying out the MLF (Hernández et al., 2007; Burns \& Osborne, 2013; Wang et al., 2018). An important point in the selection of novel LAB for use as malolactic starter cultures is to know if the selected strain will affect wine colour and/or astringency.

The fact that only $O$. oeni fermented the Pinot noir wine, and only the Patagonian strain of $L b$. plantarum fermented the Merlot wine, brought some challenges to find correlations regarding colour parameters. For instance, looking at the CIELAB parameters in Pinot noir, a decrease in redness $\left(a^{*}\right)$ was the only clear and statistically significant change after MLF. This result agrees with the increase in the hue (A420/520), which in this case denotes the relative importance of the yellowness over the redness (Zamora, 2003). And, although not statistically significant, the reduction of the chroma $\left(C^{*}\right)$ and increase of the hue $\left(H^{*}\right)$ after MLF may also be contributing to the colour of this wine variety. In fact, when analysing the $\Delta E^{*}$ component, the higher values correspond to the wines in which L-malic acid was consumed (OeATCC 27310 and UNQOe19). As a brief clarification, when $\Delta E^{*}$ is equal to or more than 2.7 CIELAB units, the wines being compared can be chromatically differentiated by the human eye, even when the variation in colour intensity (CI) is very low (Casassa \& Sari, 2006). This comparison was made against the control (no-MLF) condition.

When looking at the results for the Merlot, it is difficult to come up with a general assumption for MLF. With or without L-malic acid consumption, there was a general increase in the values of the total phenolic index (TPI), colour intensity (CI) and hue (A420/520). In contrast, there was a general and significant decrease in the CIELAB parameters, especially in the wine with successful MLF (UNQLp11). Finally, the $\Delta E^{*}$ component showed a significant difference to that of the control (no-MLF) condition, and again was higher in the wine with successful MLF. So, these results highlight that the presence of LAB might be responsible for some of these changes, even when they are not consuming L-malic acid.

We undoubtedly need more colour measurement assays 
TABLE 3

General differences in colour parameters between Pinot noir and Merlot wines, with and without L-malic acid consumption, in comparison with the control condition (no-MLF).

\begin{tabular}{|c|c|c|c|c|}
\hline \multicolumn{3}{|c|}{ Pinot noir } & \multicolumn{2}{|c|}{ Merlot } \\
\hline & MLF- & MLF+ & MLF- & MLF+ \\
\hline${ }^{1} \mathrm{TPI}$ & - & $\uparrow$ & $\uparrow$ & - \\
\hline${ }^{2}$ TAN & $\downarrow$ & $\downarrow$ & $\mathrm{nc}$ & $\downarrow$ \\
\hline${ }^{3} \mathbf{T A}$ & $\mathrm{nc}$ & $\uparrow$ & $\downarrow$ & $\uparrow$ \\
\hline${ }^{4} \mathrm{CI}$ & $\mathrm{nc}$ & $\uparrow$ & $\uparrow \uparrow$ & $\uparrow \uparrow$ \\
\hline${ }^{5} \mathrm{~A} 420 / 520$ & $\downarrow$ & $\uparrow \uparrow$ & $\uparrow \uparrow$ & $\uparrow \uparrow$ \\
\hline $\mathbf{L}^{*}$ & $\mathrm{nc}$ & $\downarrow$ & $\downarrow \downarrow$ & $\downarrow \downarrow$ \\
\hline$C^{*}$ & $\uparrow$ & $\downarrow$ & $\downarrow \downarrow$ & $\downarrow \downarrow$ \\
\hline $\mathbf{H}^{*}$ & - & $\uparrow$ & $\downarrow \downarrow$ & $\downarrow \downarrow$ \\
\hline$a^{*}$ & $\mathrm{nc}$ & $\downarrow \downarrow$ & $\downarrow \downarrow$ & $\downarrow \downarrow$ \\
\hline $\mathbf{b}^{*}$ & $\uparrow$ & $\mathrm{nc}$ & $\downarrow \downarrow$ & $\downarrow \downarrow$ \\
\hline$\Delta \mathrm{E}^{*}$ & $\uparrow$ & $\uparrow$ & $\uparrow$ & $\uparrow \uparrow$ \\
\hline
\end{tabular}

MLF-, wines that were inoculated but in which no L-malic acid consumption was detected; MLF+, wines with successful MLF. ${ }^{1}$ TPI, total polyphenolic index; ${ }^{2} \mathrm{TAN}$, tannins are expressed in $\mathrm{g} / \mathrm{L} ;{ }^{3} \mathrm{TA}$, total anthocyanins are expressed in $\mathrm{mg} / \mathrm{L} ;{ }^{4} \mathrm{CI}$, colour intensity; ${ }^{5} \mathrm{~A} 420 / 520$, hue calculated as the ratio of the absorbances obtained at 420 and $520 \mathrm{~nm}$; nc, not clear; -, values maintained. Arrows represent $\downarrow$, decrease or $\uparrow$, increase in each value. Double arrows represent significantly different values in both strains of the same species.

to complement these comparisons, as well as more $O$. oeni and $L b$. plantarum strains to successfully perform MLF in the same wine variety. We are also considering working with higher volumes of wines and to include analyses after some time of wine evolution (ageing), with or without oak addition, as the presence of wood seems to correlate well with MLF (De Revel et al., 2005; Izquierdo-Cañas et al., 2016; González-Centeno et al., 2017). In addition, we need to consider the inoculation strategy that is being used (simultaneous or sequential yeasts and LAB bacteria, and the compatibility between them), which seems to affect tannin concentration (Abrahamse \& Bartowsky, 2012; Massera et al., 2009), and/or grape variety (Dobrei et al., 2010; Mangani et al., 2011), since colour, astringency and bitterness are influenced by the concentration of anthocyanins and other phenolic compounds, and the extent of polymerisation and copigmentation, among other chemical parameters (Versari et al., 2008).

In summary, the two $O$. oeni strains used in this study completed L-malic acid consumption in Pinot noir wine but not in Merlot. Only the Patagonian Lb. plantarum strain consumed all L-malic acid in the Merlot wine, but not in the Pinot noir. The two O. oeni strains, but mostly OeATCC 27310, were able to survive in Merlot wine even when not consuming L-malic acid. From our results, we hypothesise that the phenolic composition of wine may vary depending on the LAB strain, and that a successful MLF will have a higher impact on this variation. Further work is needed to confirm these results and to increase our knowledge on this subject.

\section{CONCLUSIONS}

Different strains of $O$. oeni and $L b$. plantarum behave differently depending on wine variety, and successful MLF modifies wine colour, astringency and bitterness. Our results also demonstrate that sometimes not only $O$. oeni, but also Lb. plantarum, can be fastidious and unpredictable bacteria when inoculated into wine. This is exactly the reason why it is so important to keep studying MLF, as we still have a long road ahead to understand how different species and strains of LAB will react to different wine chemistry, and the consequences of such interaction for wine quality.

\section{LITERATURE CITED}

Abrahamse, C.E. \& Bartowsky, E.J., 2012. Timing of malolactic fermentation inoculation in Shiraz grape must and wine: Influence on chemical composition. World J. Microbiol. Biotechnol. 28, 255-265. https:// doi.org/10.1007/s11274-011-0814-3

Ayala, F., Echávarri, J.F. \& Negueruela, A.I., 1997. A new simplified method for measuring the color of wines. I. Red and rosé wines. Am. J. Enol. Vitic. 48(3), 357-363.

Bartowsky, E.J., 2017. Oenococcus oeni and the genomic era. FEMS Microbiol. Rev. 41(Supp_1): S84-S94. https://doi.org/10.1093/femsre/ fux034

Berbegal, C., Peña, N., Russo, P., Grieco, F., Pardo, I., Ferrer, S., Spano, G. \& Capozzi, V., 2016. Technological properties of Lactobacillus plantarum strains isolated from grape must fermentation. Food Microbiol. 57, 187194. https://doi.org/10.1016/j.fm.2016.03.002

Bravo-Ferrada, B.M., Gómez-Zavaglia, A., Tymczyszyn, E.E. \& Semorile, L., 2014. Effect of acclimation medium on cell viability, membrane integrity and ability to consume malic acid in synthetic wine by oenological Lactobacillus plantarum strains. J. Appl. Microbiol. 116, 360-367. https:// doi.org/10.1111/jam. 12372 
Brizuela, N.S., Bravo-Ferrada, B.M., Valdés la Hens, D., Hollmann, A., Delfederico, L., Caballero, A., Tymczyszyn, E.E. \& Semorile, L., 2017. Comparative vinifications assays with selected Patagonian strains of Oenococcus oeni and Lactobacillus plantarum. LWT Food Sci. Technol. 77, 1-8. https://doi.org/10.1016/j.lwt.2016.11.023

Brizuela, N.S., Bravo-Ferrada, B.M., Pozo-Bayón, M.A., Semorile, L. \& Tymczyszyn, E.E., 2018. Changes in the volatile profile of Pinot noir wines caused by Patagonian Lactobacillus plantarum and Oenococcus oeni. Food Res. Int. 106, 22-28. https://doi.org/10.1016/j.foodres.2017.12.032

Brizuela, N., Tymczyszyn, E.E., Semorile, L.C., Valdés la Hens, D., Delfederico, L., Hollmann, A. \& Bravo-Ferrada, B., 2019. Lactobacillus plantarum as a malolactic starter culture in winemaking: A new (old) player? Electron. J. Biotechnol. 38, 10-18. https://doi.org/10.1016/j. ejbt.2018.12.002

Burns, T.R. \& Osborne, J.P., 2013. Impact of malolactic fermentation on the color and color stability of pinot noir and merlot wine. Am. J. Enol. Vitic. 64(3), 370-377. http://10.5344/ajev.2013.13001

Casassa, F. \& Sari, S., 2006. Aplicación del sistema Cie-Lab a los vinos tintos. Correlación con algunos parámetros tradicionales. Rev. Enol. 5, 5662.

Cheynier, V., Dueñas-Paton, M., Salas, E., Maury, C., Souquet, J.M., SarniManchado, S. \& Fulcrand, H., 2006. Structure and properties of wines pigments and tannins. Am. J. Enol. Vitic. 57(3), 298-305.

Comuzzo, P. \& Battistutta, F., 2019. Acidification and pH control in red wines. In: Morata, A. (ed). Red wine technology. Academic Press, Elsevier, London, UK. pp. 17 - 34. https://doi.org/10.1016/B978-0-12-814399$5.00002-5$

Costantini, A., García-Moruno, E. \& Moreno-Arribas, M.W., 2009 Biochemical transformations produced by malolactic fermentation In: Moreno-Arribas, M.W. \& Polo, M.C. (eds). Wine chemistry and biochemistry. Springer, New York, NY. pp. $27-57$.

Costello, P.J., Francis, I.L. \& Bartowsky, E.J., 2012. Variations in the effect of malolactic fermentation on the chemical and sensory properties of Cabernet Sauvignon wine: Interactive influences of Oenococcus oeni strain and wine matrix composition. Aust. J. Grape Wine Res. 18(3), 287-301. https://doi.org/10.1111/j.1755-0238.2012.00196.x

De Revel, G., Bloem, A., Augustin, M., Lonvaud-Funel, A. \& Bertrand, A., 2005. Interaction of Oenococcus oeni and oak wood compounds. Food Mircrobiol. 22, 569-575.

Dobrei, A., Poiana, M.A., Sala, F., Ghita, A. \& Gergen, I., 2010. Changes in the chromatic properties of red wines from Vitis vinifera L. cv. Merlot and Pinot noir during the course of aging in bottle. J. Food Agric. Environ. 8(2), 20-24. https://doi.org/10.1016/j.aaspro.2016.09.056

Durán, O.D.S. \& Trujillo, N.Y.Y., 2008. Estudio comparativo del contenido fenólico de vinos tintos colombianos e importados. Viate, Revista de la Facultad de Química Farmacéutica, 15(1), 17-24.

Du Toit, M., Engelbrecht, L., Lerm, E. \& Krieger-Weber, S., 2011. Lactobacillus: The next generation of malolactic fermentation starter cultures - an overview. Food Bioprocess Technol. 4, 876-906. https://doi. org/10.1007/s11947-010-0448-8

Elorduy Vidal, X.L., 2014. Caracterización de vinos tintos de varias denominaciones de origen catalanas en base a los vinos presentes en el mercado. DO Tarragona, DO Conca de Barberà y DOQ Priorat. Thesis, Universitat Politècnica de València. https://riunet.upv.es/ handle/10251/35893

Garrido, J. \& Borges, F., 2013. Wine and grape polyphenols - a chemical perspective. Food Res. Int. 54, 1844-1858. https://doi.org/10.1016/j. foodres.2013.08.002

Glories, Y., 1984. La couleur des vins rouges. 1re partie: les equilibres des anthocyanes et des tannins. Connaiss. Vigne. Vin. 18(3), 195-217.
González-Centeno, M.R., Chira, K. \& Teissedre, P.L., 2017. Comparison between malolactic fermentation container and barrel toasting effects on phenolic, volatile and sensory profile of red wines. J. Agric. Food. Chem. 65(16), 3320-3329. https://doi.org/10.1021/acs.jafc.6b05497

Hernández, T., Estrella, I, Pérez-Gordo, M., Alegría, E.G., Tenorio, C., Ruiz-Larrea, F. \& Moreno-Arribas, M.V., 2007. Contribution of malolactic fermentation by Oenococcus oeni and Lactobacillus plantarum to the changes in the nonanthocyanin polyphenolic composition of red wine. J. Agric. Food. Chem. 55, 5260-5266. https://doi.org/10.1021/jf063638o

Izquierdo-Cañas, P.M., Mena-Morales, A. \& García-Romero, E., 2005 Interaction of Oenococcus oeni and oak wood compounds. Food Microbiol. 22, 569-575. https://doi.org/10.1016/j.fm.2004.11.006

Izquierdo-Cañas, P.M., Mena-Morales, A., García-Romero, E., 2016. Malolactic fermentation before or during wine aging in barrels. LWT Food Sci. Technol. 66, 468-474.

Krieger-Weber, S., Heras, J.M. \& Suarez, C., 2020. Lactobacillus plantarum, a new biological tool to control malolactic fermentation: A review and an outlook. Beverages 6, 1-23. https://doi.org/10.3390/beverages6020023

Lonvaud-Funel, A., 2015. Lactic acid bacteria and malolactic fermentation in wine. In: Mozzi, F., Raya, R.R. \& Vignolo, G.M. (eds). Biotechnology of lactic acid bacteria. John Wiley \& Sons, Ltd, pp. 231 - 247. https://doi. org/10.1002/9781118868386.ch15

Lorentzen, M.P.G. \& Lucas, P.M., 2019. Distribution of Oenococcus oeni population in natural habitats. Appl. Microbiol. Biotechnol. 103, 29372945. https://doi.org/10.1007/s00253-019-09689-z

Mangani, S., Buscioni, G., Collina, L., Bocci, E. \& Vicenzini, M., 2011. Effects of microbial populations on anthocyanin profile of Sangiovese wines produced in Tuscany, Italy. Am. J. Enol. Vitic. 62(4), 487-493. http://10.5344/ajev.2011.11047

Massera, A., Soria, A., Catania, C., Krieger, S. \& Combina, M., 2009 Simultaneous inoculation of Malbec (Vitis vinifera) musts with yeast and bacteria: Effects on fermentation performance, sensory and sanitary attributes of wines. Food Technol. Biotechnol. 47(2), 192-201.

Nel, A.P., 2018. Tannins and anthocyanins: From their origin to wine analysis - a review. S. Afr. J. Enol. Vitic. 39(1), 1-20. http://dx.doi. org/10.21548/39-1-1503

Organización Internacional de la Viña y el Vino, 2009. Compendium of International Methods of Wine and Must Analysis. Vol. II, Sect 3. Paris: OIV.

Olguin, N.T., Valdés la Hens, D., Delfederico, L. \& Semorile, L., 2019. Relative expression of stress-related genes during acclimation at low temperatures of psychrotrophic Oenococcus oeni strains from Patagonian wine. World J. Microbiol. Biotechnol. 35(5), 1-9. https://doi.org/10.1007/ s11274-018-2577-6

Paladino, S., Galiotti, H.C. \& Formento, J.C., 2001. La fermentación maloláctica y el color de vinos tintos. Rev. UNCuyo Tomo XXXIII(2), 105 110 .

Pandeya, A., Rayamajhi, S., Pokhrel, P. \& Giri, B., 2018. Evaluation of secondary metabolites, antioxidant activity, and color parameters of Nepali wines. Wiley Food Sci. Nut. 6(8), 2252-2263. https://doi.org/10.1002/ fsn3.794

Renouf, V., Perello, M.C., de Revel, G. \& Lonvaud-Funel, A., 2007. Survival of wine microorganisms in the bottle during storage. Am. J. Enol. Vitic. 58(3), 379-386.

Ribéreau-Gayon, P., Glories, Y., Maujean, A., Dubourdieu, D., 2006. Phenolic compounds. In: Ribéreau-Gayon, P., Glories, Y., Maujean, A. Dubourdieu, D., (Eds.), Handbook of enology. The chemistry of wine stabilisation and treatments (Vol. 2, pp. 141-203). John Wiley \& Sons Ltd. Southern Gate, Chichester, England. https://doi.org/10.1002/0470010398. ch6 
Sumby, K.M, Bartle, L., Grbin, P.R. \& Jiranek, V., 2019. Measures to improve wine malolactic fermentation. Appl. Microbiol. Biotechnol. 103, 2033-2051. https://doi.org/10.1007/s00253-018-09608-8

Versari, A., Boulton, R.B. \& Parpinello, G.P., 2008. A comparison of analytical methods for measuring the color components of red wines. Food Chem. 106(1), 397-402. https://doi.org/10.1016/j.foodchem.2007.05.073

Vivas, N., Bellemere, L., Lonvaud-Funel, A., Glories, Y. \& Augustin, M., 1994. Etudes sur la fermentation malolactique des vins rouges en barrique et en cuves. Revue Française d'Enologie 151, 39-45.
Wang, S., Li, S., Zhao, H., Gu, P., Chen, Y., Zhang, B. \& Zhu, B., 2018. Acetaldehyde released by Lactobacillus plantarum enhances accumulation of pyranoanthocyanins in wine during malolactic fermentation. Food Res. Int. 108, 254-263. https://doi.org/10.1016/j.foodres.2018.03.032

Zamora, F., 2003. Elaboración y crianza del vino tinto. Aspectos científicos y prácticos. Ed. Mundi-Prensa, Madrid, España. pp. 53 - 69). 